\title{
Epidemiological Analysis of Salmonella Enterica Serovar Typhimurium and Serovar 1,4,[5],12:i:- Isolates Determined by Pulsed Field Gel Electrophoresis and Antibiotic Susceptibility: Comparison of Isolates from Broiler Chickens, Humans and the Environment in Reunion Island
}

\author{
Isabelle Henry ${ }^{*}, 1$, Marianne Chemaly ${ }^{2}$, Sophie Granier $^{3}$, Françoise Lalande ${ }^{2}$, Céline Courtillon ${ }^{2}$, \\ Gilles Salvat ${ }^{2}$ and Eric Cardinale ${ }^{4}$
}

\author{
${ }^{1}$ Crête d'Or Entreprise, 4 ave Michel de Debré, 97427 Etang Salé, Réunion, France \\ ${ }^{2}$ Afssa Unité HQPAP, Site des croix des fusillés, 22440 Ploufragan, France \\ ${ }^{3}$ Afssa CEB, 23 ave Général de Gaulle, 94706 Maisons Alfort Cedex, France \\ ${ }^{4}$ Cirad Bios, 2 rue Maxime Rivière, 97490 Ste Clotilde, Réunion. Mail : 2 rue Maxime Rivière, 97490 Ste Clotilde, \\ Réunion
}

\begin{abstract}
Salmonella enterica ssp. enterica is a leading cause of bacterial food-borne disease outbreaks worldwide and is also an economic burden particularly in Reunion Island because its population consumes large amounts of chicken and cooks $100 \%$ chicken sausages (35 kg per capita per year).

The aim of this study was to investigate the epidemiology of Salmonella Typhimurium and Salmonella 1,4,[5],12:i:- from broiler chickens, humans and the environment by using pulsed field gel electrophoresis (PFGE) and antibiotic susceptibility and to assess the significance of broiler chicken meat as a source of human infection.

A total of 157 Salmonella Typhimurium and 19 S. I 4,[5],12:i:- were collected and isolated from broiler chickens, humans and the environment between October 2007 and January 2009. The PFGE of Xbal digested chromosomal DNA gave 30 distinct profiles for Salmonella Typhimurium and S. 1,4,[5],12:i:-. Salmonella Typhimurium was characterized by a main pulsotype (B54) and accounted for 32\% of all isolates. This pulsotype included isolates from many sources such as broiler chickens, poultry houses, slaughterhouses, other animal species (ducks, pigs and rodents) and humans, suggesting that it had already colonized every step of the food chain. Antibiotic susceptibility tests showed that most isolates were resistant to ampicillin, streptomycin, sulfonamides and tetracycline.

The similarity of PFGE profiles of isolates from various sources and particularly from poultry and humans underlined possible transmission of Salmonella from contaminated broiler meat, but most of the isolates remained drug-sensitive.

Significance and impact of study: Efforts are needed to eliminate Salmonella from poultry meat destined for human consumption. This study has also shown the importance of monitoring antimicrobial resistance in bacteria associated with animals and humans.
\end{abstract}

Keywords: Antibiotic susceptibility, broiler chickens, humans, PFGE, reunion Island, salmonella

\section{INTRODUCTION}

"Salmonella is a leading cause of bacterial food-borne disease outbreaks in temperate countries [1] and is also a public health concern in tropical countries" $[2,3]$.

"The most commonly implicated foods in outbreaks of human salmonellosis are those of animal origin" [4]. "Most of these infections have been attributed to the consumption of poultry meat and eggs" [5]. "Salmonella enterica subsp. enterica serovar Typhimurium is one of the most common

*Address correspondence to this author at the Isabelle Henry, Crête d'Or Entreprise, 4 ave Michel de Debré, 97427 Etang Salé, Réunion, France; Tel: 0262265900; Fax: 0262265901;

E-mail: ch.recherche@avicom.re serovars isolated from humans, animals and food in Europe and the United States [6,7]. In France, Salmonella Typhimurium, $S$. Enteritidis, and $S$. 1,4,[5],12:i:- were the serovars most frequently isolated in 2008 at $46 \%, 19 \%$ and $4 \%$ of clinical isolates, respectively. Furthermore, during the last decade Salmonella 1,4,[5],12:i:- has emerged around the world [8], and this isolate could be a monophasic isolate of serotype Typhimurium.

Salmonella causes diverse disease syndromes ranging from asymptomatic colonization to severe intestinal illness [9]. Antimicrobial therapy may be needed; fluoroquinolones and $\beta$ lactams are the antibiotic drugs of choice. Nevertheless, global outbreaks of multidrug-resistant Salmonella have been reported, particularly for S. Typhimurium. Resistance to fluoroquinolones and extended spectrum cephalosporins is still growing in the 
European Union, Africa [10] and Asia, for example in Japan where a high level of fluoroquinolone-resistant isolates was first identified in 2000 [11]. Resistance is of utmost importance to worldwide public health, and controlling antimicrobial resistance is important to limit the transfer of resistant Salmonella from animals to humans.

Salmonella from poultry have been studied all over the world but no epidemiological study had previously been undertaken in Reunion Island. This island is located in the Indian Ocean, east of Madagascar and west of Mauritius. Reunion is an administrative region of France. Chicken meat production is locally consumed (providing $66 \%$ of chicken consumption, with $33 \%$ from frozen chicken imported from France). Contamination of chicken with Salmonella is both a public health and an economic concern especially since the population of Reunion Island consumes a large amount of chicken (35 kg per capita per year) and cooks $100 \%$ chicken sausages.

The aim of this study was to investigate the molecular epidemiology of S. Typhimurium and S. 1,4,[5],12:i:- from broiler chickens, humans and the environment using pulsed field gel electrophoresis (PFGE) and antibiotic susceptibility and to assess the significance of broiler chicken meat as a source of human infection in Reunion Island.

\section{MATERIALS AND METHODS}

\section{Sample Collection}

Between October 2007 and January 2009, a total of 157 Salmonella enterica serovar Typhimurium and 19 Salmonella 1,4,[5],12:i:- isolates were collected and isolated on Reunion Island from broiler chickens, poultry farms, slaughterhouses, other animals (pigs, ducks, turkeys and rodents) and humans (Table 1).

The poultry isolates all came from live broiler chickens (faeces and litter) and from carcasses. The environment isolates came from farm environment (changing room, wall and equipment, poultry house surroundings, litter beetles (tenebrionidae), trucks (wheels) and rodents, from abattoir environment (transport crates, scalding water, defeathering and evisceration stages, trussing and cutting tables, utensils and from sausages) and from other animals (ducks, turkeys, geese...).

Isolates from pigs were acquired from a previous study [12] and some isolates from ducks and turkeys were obtained from the local veterinary laboratory.

For humans, isolates were received from the main hospital in the south of Reunion Island, private laboratories and from the Pasteur Institute in Paris, France.

\section{Microbiological Methods}

Salmonella strains were isolated by the standard culture method in accordance with NF U47-100:2007 (French Standards Association) as previously described [13]. All Salmonella isolates were serotyped according to the Kauffmann-White scheme [14] and the slide agglutination test using Salmonella polyvalent $\mathrm{O}$ and $\mathrm{H}$ antisera in accordance with the Diagnostic Pasteur.

\section{Molecular Typing: RFLP/PFGE}

\section{DNA Extraction}

The following harmonized protocol was used for the study as described previously [15]. After overnight growth on PCA or nutrient broth, cells were harvested by centrifugation and re-suspended in suspension buffer. The final cell density for plug preparation was $1.3-1.6$ at $600 \mathrm{~nm}$. Proteinase $\mathrm{K}$ was added to the cell suspension followed by mixing lysis of cell suspension 1:1 with SeaKem Gold Agarose. The resultant plugs were washed at least twice in distilled water and four times in TE buffer.

\section{Enzymatic Digestion}

The genetic typing was carried out using the RFLPPFGE PulseNet protocol [16] and total DNA was digested with one restriction enzyme XbaI (Roche Applied Science). The obtained fragments were separated in $1 \%$ agarose (SeaKem Gold Agarose) gels using the CHEF-DR-III system (Bio-Rad Laboratories, USA).

\section{Electrophoresis}

Electrophoresis was carried out with $0.5 \mathrm{X}$ TBE buffer at $6 \mathrm{~V} / \mathrm{cm}$ and $14^{\circ} \mathrm{C}$. The running time was 20 hours and the pulse ramp time was 2.2-63.8 s. Salmonella enterica serovar Braenderup H9812 was used as a molecular weight marker.

Gels were visualized on a UV transilluminator and photographs were captured using a digital imaging system (Video gel doc system, Bio-Rad). Fragment restriction patterns were analysed by BioNumerics software (Applied Maths, Sint Marteen, Belgium), performed using UPGMA (unweighted pair-group method with an arithmetic mean) and a Dice similarity coefficient [17] with a tolerance index of $5 \%$, a position tolerance setting of $1 \%$ and an optimization setting of $1 \%$ generating a dendrogram. Fragments smaller than $30 \mathrm{~kb}$ were disregarded in accordance with the PulseNet guidelines for standardization [18].

\section{Discrimination Power}

Discrimination power was calculated by determining the Simpson discrimination indices (D) as per Hunter [19]. These values represent the probability that two distinct isolates will be ranged into different typing groups.

\section{Antimicrobial Susceptibility Testing}

Antimicrobial susceptibility was tested by the disk diffusion method following the CLSI guidelines (Clinical and Laboratory Standards Institute, 2008).

The isolates were tested for their susceptibility to ampicilin (A; $10 \mu \mathrm{g}$ ), amoxicillin-clavulanic acid (AMC; 20/10 $\mu \mathrm{g}$ ), cefotaxime (CTX; $30 \mu \mathrm{g}$ ), chloramphenicol (C; $30 \mu \mathrm{g}$ ), cephalothin (CF; $30 \mu \mathrm{g}$ ), ceftazidime (CAZ; $30 \mu \mathrm{g}$ ), cotrimoxazole (SXT; $1.25 / 23.75 \mu \mathrm{g})$, sulfonamides - 
Table 1. Type of samples and PFGE pattern of Salmonella Typhimurium and Salmonella S. 1,4,[5],12:i:- collected from broiler chickens, farms and the slaughterhouse, from other animals, humans and from some foodstuffs (Reunion Island, 20072009, 176 isolates).

\begin{tabular}{|c|c|c|c|c|}
\hline \multicolumn{3}{|c|}{ Type of Samples } & \multirow{2}{*}{$\begin{array}{c}\text { Number of Isolated Strains (\%) } \\
33(19)\end{array}$} & \multirow{2}{*}{$\begin{array}{l}\text { PFGE Pattern (Number of Each Pulsotype) } \\
\mathrm{B} 50(8) ; \mathrm{B} 52(4) ; \mathrm{B} 54(12) ; \mathrm{B} 59(1) ; \mathrm{B} 61(1) ; \mathrm{B} 63(1) ; \\
\mathrm{B} 64(1) ; \mathrm{B} 70(1) ; \mathrm{B} 75(1) ; \mathrm{B} 77(3)\end{array}$} \\
\hline Broiler chicken & Broiler chicken & Faeces and litter & & \\
\hline & & Caeca & $5(3)$ & $\mathrm{B} 54(2) ; \mathrm{B} 62(1) ; \mathrm{B} 73(1)$ \\
\hline & & Carcasses & $19(11)$ & $\mathrm{B} 54(5) ; \mathrm{B} 62(4) ; \mathrm{B} 69(1) ; \mathrm{B} 73(6) ; \mathrm{B} 74(1) ; \mathrm{B} 77(2)$ \\
\hline \multirow{12}{*}{ Environment } & & Sas & $3(2)$ & B54(1);B62(2) \\
\hline & & Surroundings & $2(1)$ & B58(1);B69(1) \\
\hline & Slaughter house & Transport crate & $3(2)$ & $\mathrm{B} 50(2) ; \mathrm{B} 62(1) ; \mathrm{B} 73(1)$ \\
\hline & & Scalding water & $3(2)$ & $\mathrm{B} 50(2) ; \mathrm{B} 51(1)$ \\
\hline & & After trussing table & $6(3)$ & $\mathrm{B} 54(2) ; \mathrm{B} 69(1) ; \mathrm{B} 73(2) ; \mathrm{B} 77(1)$ \\
\hline & & Evisceration & $6(3)$ & $\mathrm{B} 54(4) ; \mathrm{B} 73(1) ; \mathrm{B} 77(1)$ \\
\hline & & Cutting tables & $5(3)$ & $\mathrm{B} 54(1) ; \mathrm{B} 72(2) ; \mathrm{B} 73(2)$ \\
\hline & & Utensils & $1(1)$ & $\mathrm{B} 77(1)$ \\
\hline & Other animals & Pig & $11(6)$ & $\mathrm{B} 54(4) ; \mathrm{B} 61(2) ; \mathrm{B} 64(2) ; \mathrm{B} 69(1) ; \mathrm{B} 72(1)$ \\
\hline & & Duck & $10(6)$ & B51(5);B52(1);B54(1);B56(3) \\
\hline & & Rooster & $4(2)$ & B54(4) \\
\hline & & Turkey & $5(3)$ & B54(3);B62(1);B71(1) \\
\hline Food stuff & & Sausage & $1(1)$ & B73(1) \\
\hline
\end{tabular}

NCCLS $(\mathrm{Su} ; 300 \mu \mathrm{g})$, gentamicin $(\mathrm{Gm} ; 10 \mu \mathrm{g})$, streptomycin $(\mathrm{S} ; 10 \mu \mathrm{g})$, kanamycine $(\mathrm{K} ; 30 \mu \mathrm{g})$, tetracycline $(\mathrm{T} ; 30 \mu \mathrm{g})$, colistine $(\mathrm{Cs} ; 10 \mu \mathrm{g})$, nalidixic acid $(\mathrm{Na} ; 30 \mu \mathrm{g})$, ofloxacine (Ofx; $5 \mu \mathrm{g})$ and enrofloxacine (Enr; $5 \mu \mathrm{g})$. Escherichia coli (ATCC25922) was used as control strain.

\section{RESULTS}

\section{PFGE and Genetic Diversity}

The genotyping of 157 isolates of Salmonella Typhimurium and 19 isolates of $S$. 1,4,[5],12:i:- was carried out by PFGE using Xbal as macrorestriction enzyme. Digestion of DNA revealed 30 profiles (B49 to B78) (Fig. 2). The discriminatory ability ( $\mathrm{D}$ value) of the method was 0.86 for the entire panel. Analysis by BioNumerics software showed an overall similarity of $75 \%$ with stable patterns consisting of 14-18 fragments.
The genetic relatedness of the PFGE profiles for Salmonella Typhimurium and $S$. 1,4,[5],12:i:- showed 5 clusters (Fig. 1) but $S$. 1,4,[5],12:i:- was only found in clusters 4 and 5 : the first cluster $(17.3 \%$ of the isolates) consisted of 6 profiles (B49, B50, B51, B52, B53 and B59): 12 isolates from chicken, 4 from the slaughterhouse (2 from scalding water, 1 from the defeathering stage and 1 from transport crates), 8 from other animals ( 2 turkeys, 6 ducks), 5 from humans and 2 from sausages. The second cluster $(35.7 \%)$ consisted of 5 profiles (B54, B55, B56, B57 and B58) from 24 chicken isolates, 11 from broiler farms and slaughterhouses (outdoor area, changing rooms, walls and equipment, transport crates, scalding water, evisceration and cutting table); 14 from other animals (rodent, turkey, wild bird and duck isolates) and 15 from humans; the third cluster $(12.8 \%$ of the isolates) comprised 3 profiles (B62, B63 and B64): 11 from chickens, 5 from farm and abattoir 
Dice (Opt:1.00\%) (Tol 1.0\%-1.0\%) (H>0.0\% S>0.0\%) [0.0\%-100.0\%] PFGE-Xbal PFGE-Xbal
PFal

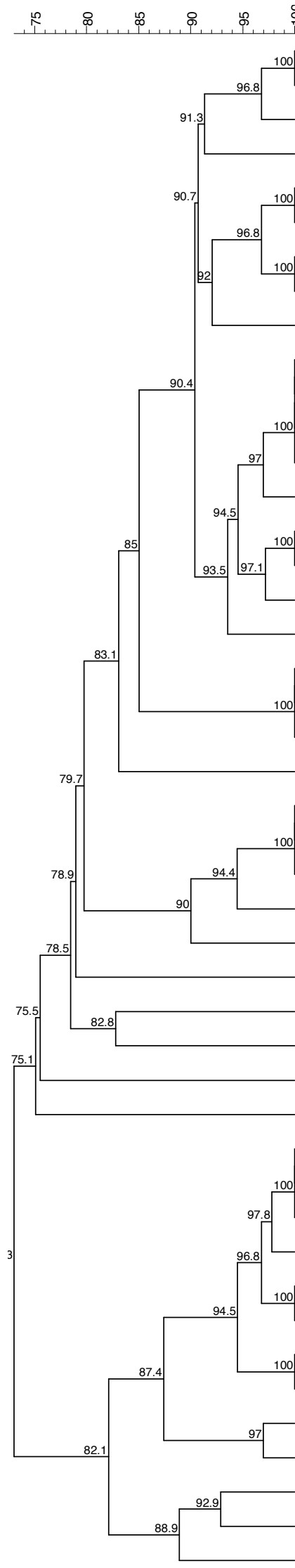

Key

$\mathrm{IH}-241$

$\mathrm{IH}-340$

$\mathrm{IH}-294$

$\mathrm{IH}-277$

$\mathrm{IH}-342$

$\mathrm{IH}-409$

$\mathrm{IH}-262$

$\mathrm{IH}-396$

$\mathrm{IH}-299$

$\mathrm{IH}-212$

$\mathrm{IH}-235$

$\mathrm{IH}-242$

$\mathrm{IH}-288$

$\mathrm{IH}-231$

$\mathrm{IH}-237$

$\mathrm{IH}-422$

$\mathrm{IH}-286$

$\mathrm{IH}-247$

$\mathrm{IH}-291$

$\mathrm{IH}-351$

$\mathrm{IH}-408$

IH-269

$\mathrm{IH}-233$

$\mathrm{IH}-245$

$\mathrm{IH}-276$

$\mathrm{IH}-312$

$\mathrm{IH}-411$

IH- 419

$\mathrm{IH}-397$

$\mathrm{IH}-410$

IH- 413

IH-258

$\mathrm{IH}-203$

$\mathrm{IH}-315$

$\mathrm{IH}-403$

(H-403

$\mathrm{IH}-421$

IH-395

$\mathrm{IH}-423$

IH-224

IH-317

IH-249

IH-254

$\mathrm{IH}-337$

IH-399

IH-319

\section{Xbal Genre}

B53 Salmonella

B53 Salmonella

B52 Salmonella

B51 Salmonella

B49 Salmonella

B49 Salmonella

B50 Salmonella

B50 Salmonella

B59 Salmonella

B54 Salmonella

B54 Salmonella

B54 Salmonella

B54 Salmonella

B55 Salmonella

B56 Salmonella

B56 Salmonella

B57 Salmonella

B58 Salmonella

B61 Salmonella

B61 Salmonella

B61 Salmonella

B60 Salmonella

B62 Salmonella

B62 Salmonella

B62 Salmonella

B63 Salmonella

B64 Salmonella

B77 Salmonella

B65 Salmonella

B66 Salmonella

B68 Salmonella

B67 Salmonella

B69 Salmonella

B69 Salmonella

B69 Salmonella

B70 Salmonella

B71 Salmonella

B71 Salmonella

B72 Salmonella

B72 Salmonella

B73 Salmonella

B74 Salmonella

B75 Salmonella

B78 Salmonella

B76 Salmonella
Serotype Origin

Typhimurium Human

Typhimurium Poultry

Typhimurium Poultry

Typhimurium Poultry

Typhimurium Poultry

Typhimurium Human

Typhimurium Poultry

Typhimurium Human

Typhimurium Poultry

Typhimurium Poultry

Typhimurium Rodent

Typhimurium Human

Typhimurium Poultry

Typhimurium Poultry

Typhimurium Human

Typhimurium Poultry

Typhimurium Human

Typhimurium Poultry

Typhimurium Poultry

Typhimurium Poultry

Typhimurium Human

Typhimurium Poultry

Typhimurium Poultry

Typhimurium Human

Typhimurium Poultry

Typhimurium Poultry

Typhimurium Human

Typhimurium Poultry

Typhimurium Human

Typhimurium Human

Typhimurium Human

Typhimurium Poultry

S.I 4,12:i:- Poultry

Typhimurium Pork

Typhimurium Human

Typhimurium Poultry

Typhimurium Human

Typhimurium Poultry

Typhimurium Poultry

Typhimurium Pork

Typhimurium Poultry

Typhimurium Poultry

Typhimurium Poultry

Typhimurium Human

S.I 4,12:i:- Poultry

Fig. (1). Dendrogram showing the cluster analysis of PFGE Xba1 patterns from 161 isolates of Salmonella Typhimurium and 18 Salmonella 1,4,[5],12:i:- generated by BioNumerics software using the UPGMA method. 


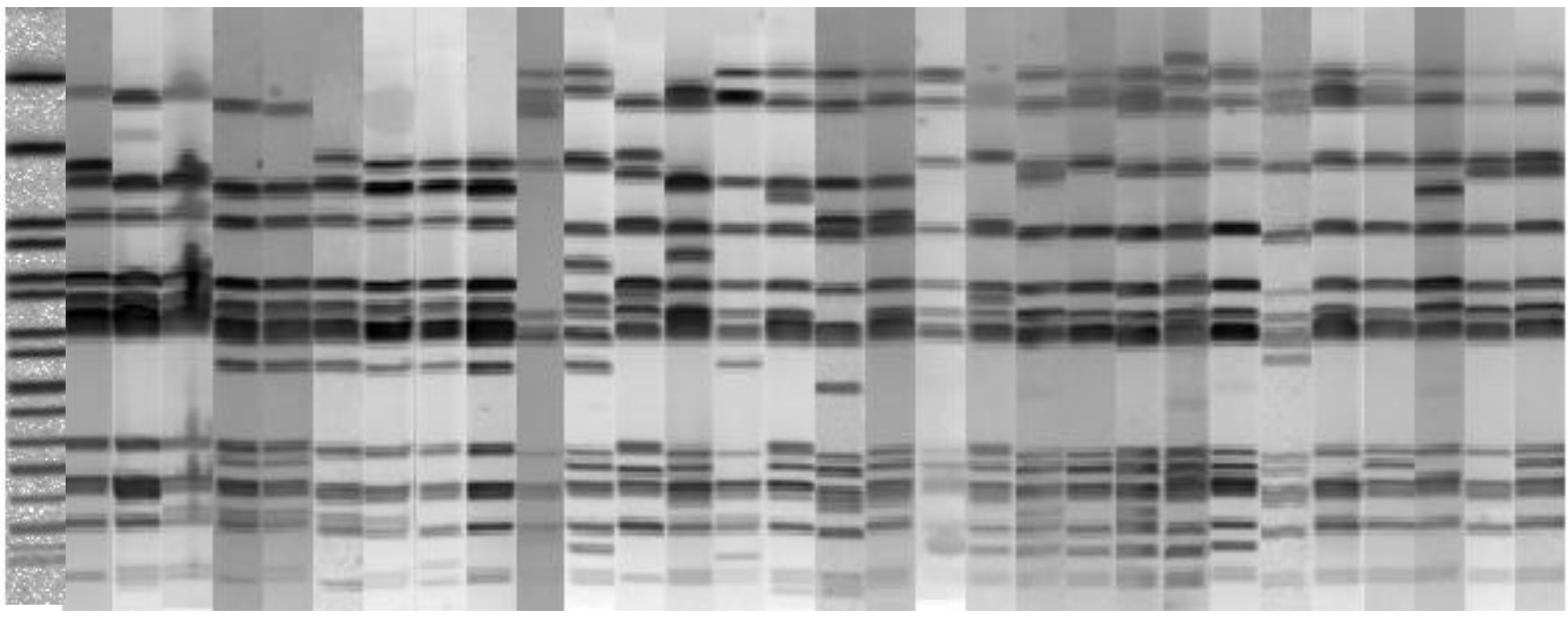

Fig. (2). The PFGE Type for Xba1 digested genome DNA of Salmonella Typhimurium and Salmonella S. 1,4,[5],12:i:- . A total of 176 isolates were analysed; 30 Xba1 PFGE-types were obtained: M:Salmonella Braenderup; lane1:B76; lane2:B78; lane3:B75; lane4:B74; lane5:B73; lane6:B72; lane7:B71; lane8:B70; lane9:B69; lane10:B67; lane11:B68; lane12:B66; lane13:B65; lane14:B77; lane15:B64; lane16:B63; lane17:B62; lane18:B60; lane19:B61; lane20:B58; lane21:B57; lane22:B56; lane23:B55; lane24:B54; lane25:B59; lane26:B50; lane27:B49; lane28:B51; lane29:B52; lane30:B53.

environment (changing rooms, transport crates, defeathering and evisceration stages), 4 from other animals (pigs, turkeys and guinea fowl) and 3 from humans; the fourth cluster (7.8\% of the isolates) comprised 4 profiles (B69, B70, B71 and B72): 1 from chicken, 3 from farm and abattoir environment (outdoor area and cutting table), 3 from other animals (pigs and turkey) and 2 from humans for $S$. Typhimurium; for $S$. 1,4,[5],12:i:-, the fourth cluster comprised 1 isolate from chicken, 1 human and 3 isolates from the slaughterhouse environment (defeathering stage and trussing table). Finally, the fifth cluster $(10.6 \%$ of the isolates) comprised 2 profiles (B73 and B74): 2 isolates from chickens, 4 from the slaughterhouse environment (defeathering and evisceration stages, trussing and cutting tables) and 1 from sausages for $S$. Typhimurium; 6 chicken isolates and 6 isolates from the abattoir environment (transport crates, defeathering stage, cutting and trussing tables) were found for $S .1,4,[5], 12: \mathrm{i}:-$.

\section{Antibiotic Resistance Patterns}

Salmonella Typhimurium. Among a total of 157 Salmonella Typhimurium isolates, $9(5.5 \%)$ were resistant to A, $28(17.4 \%)$ to $\mathrm{S}, 32(19.9 \%)$ to $\mathrm{Su}, 4(2.5 \%)$ to SXT and $37(22.3 \%)$ to $\mathrm{T}$. The same results were observed for isolates from the environment or humans (Table 2). Only 1 isolate from other animals exhibited a resistance against $\mathrm{Na}$.

Salmonella 1,4,[5],12:i:-. Out of 19 isolates, 19 (100\%) was resistant to $\mathrm{A}, \mathrm{S}, \mathrm{Su}$ and $\mathrm{T}$.

\section{Antibiotic Resistance Associated with PFGE Pattern}

The main resistance pattern associated with most of the pulsotypes (B50, B69, B70, B71, B73, B74, B75 and B76) is $\mathrm{A}, \mathrm{S}, \mathrm{Su}, \mathrm{T}$. We also found two other resistance patterns: A,Su,SXT,T (B62 and B63) and S,Su,T (B54 and B55).
Three isolates from pig and human origin yielded the typical multidrug resistant pattern $\mathrm{A}, \mathrm{C}, \mathrm{S}, \mathrm{Su}, \mathrm{T}$ (Table 3).

\section{DISCUSSION}

In Reunion Island, S. Typhimurium is the most prominent serovar in broiler chickens, just as in other parts of the world [20-22]. It appeared that S. Typhimurium was able to infect many hosts, including monogastric species, poultry (chicken, duck, turkey, guinea fowl, geese) and pigs, but also small mammals such as rodents [23, 24]. The atypical Salmonella enterica 1,4,[5],12:1:- emerged a few years ago in Reunion Island and because of the close genetic relationship, it is certainly a monophasic isolate of S. Typhimurium [8]. Many studies have already explained the relationships between serovars S.1,4,[5],12:i:- and Typhimurium through the presence of IS200 by DNA microarray $[25,26]$.

We opted for the method of choice for typing Salmonella; pulsed field gel electrophoresis (PFGE) remains the gold standard for Salmonella genotyping. Its discriminatory power is good and this method has proved to be highly useful in outbreak situations and has been widely used for Salmonella fingerprinting [22,27,28]. Use of PFGE with endonuclease $X b a 1$ has been recognized as a precise means for fingerprinting Salmonella serovars [29], particularly for S. Typhimurium [30].

The strong similarity found between isolates from broiler chickens, humans and the environment indicated a close genetic relationship between avian serovars Typhimurium and 1,4,[5],12:i:- compared to that of isolates from other sources. Previous studies on clonal relationships of $S$. Typhimurium from humans and various other sources showed that isolates of this serovar were clustered into a group with similarity of more than $70 \%$. This observation was in agreement with our findings $(75.1 \%$ similarity). In spite of their close genetic relationship, it was possible to 
Table 2. Antimicrobial resistance for Salmonella Typhimurium and 1,4,[5],12:i:- isolates from chickens, the environment, other animals and humans.

\begin{tabular}{|c|c|c|c|c|c|c|c|c|}
\hline & \multicolumn{8}{|c|}{ Origin } \\
\hline & \multicolumn{2}{|c|}{ Chicken } & \multicolumn{2}{|c|}{ Environment } & \multicolumn{2}{|c|}{ Other animals } & \multicolumn{2}{|c|}{ Human } \\
\hline & S. Typhimurium & S 1,4,[5],12:i:- & S. Typhimurium & S 1,4,[5],12:i:- & S. Typhimurium & S 1,4,[5],12:i:- & S. Typhimurium & S 1,4,[5],12:i:- \\
\hline Ampicilin (Am) & $9(5.6)$ & $6(33.3)$ & $7(4.3)$ & $9(50)$ & $6(3.7)$ & $1(5.5)$ & $4(2.5)$ & $1(5.5)$ \\
\hline \multicolumn{9}{|l|}{$\begin{array}{l}\text { Amoxicilinc } \\
\text { lavulanic acid (AMC) }\end{array}$} \\
\hline \multicolumn{9}{|l|}{ Ceftazidime (CAZ) } \\
\hline \multicolumn{9}{|l|}{ Cephalotin $\left(\mathrm{Cf}^{\circ}\right)$} \\
\hline \multicolumn{9}{|l|}{ Colistine (CS } \\
\hline \multicolumn{9}{|l|}{ Cefotaxime (CTX) } \\
\hline Nalidixic Acid (NA) & & & & & $1(0.6)$ & & & \\
\hline \multicolumn{9}{|l|}{ Ofloxacine (OFX } \\
\hline Streptomycine (S) & $28(17.4)$ & $6(33.3$ & $17(10.5)$ & $9(50)$ & $15(9.3$ & $1(5.5)$ & $16(10 \%)$ & $1(5.5)$ \\
\hline Sulfonamides (SSS250 & $32(19.9)$ & $6(33.3)$ & $18(11.2)$ & $9(50)$ & $18(11.2)$ & $1(5.5)$ & $18(11.2)$ & $1(5.5)$ \\
\hline Cotrimoxazole (SXT) & $4(2.5)$ & & $1(0.6)$ & & $2(1.2)$ & & $3(1.9)$ & \\
\hline Tetracyclin (Te) & $37(22.3)$ & $6(33.3)$ & $23(14.3)$ & $9(50)$ & 19(11.8) & $1(5.5)$ & 19(11.8) & $1(5.5)$ \\
\hline
\end{tabular}

(): numbers in parentheses represent percentage of resistant isolates for Typhimurium and 1,4,[5],12:i:- respectively.

divide the majority of the avian isolates into five clusters. The first two and the last two clusters were closely related; this suggested, at least, the introduction of two or three different clones that could have been brought in via imports of foodstuffs, parent stocks, hatching eggs or one-day-old chicks from France or from south-east Asia [31, 32] in the 1980s.

The main pulsotype (B54) accounted for $29 \%$ of all the isolates; it comprised isolates from many sources such as poultry houses, the slaughterhouse, other animal species (ducks, turkeys, pigs or rodents) and humans, suggesting that this pulsotype had already colonized every step of the food chain [33]. This pulsotype also showed a close genetic relationship between the isolates from broilers and those from rodents. As demonstrated by Meerburg and Kijlstra [34], rodents are often implicated in the infection of poultry. Indeed, rodents have been recognized as a vehicle for Salmonella [23,35]. In Reunion Island, rodents are a real problem because most of the territory is covered with sugarcane fields, which provide a natural habitat for rodents, and are usually very close to poultry farms [36, 37].

The same pulsotypes of Salmonella have been recovered from different animal species; in a tropical island like Reunion where all farms (pig and poultry) are concentrated in a small area, exchange of organic material and pathogens between these farms via trucks, employees and technical staff is still possible. Moreover, many farmers rear pigs and broilers at the same time on the same site [12]. A cycle of transmission between these different species could have been instigated and this could explain the close genetic relationship between these Salmonella isolates [38].

Most of the chicken isolates $\left(2^{\text {nd }}, 4^{\text {th }}\right.$ and $5^{\text {th }}$ clusters $)$ had the same genotype pattern as the environmental isolates from the outdoor areas of poultry farms; this suggested Salmonella Typhimurium isolates could persist in the environment even after cleaning and disinfection [39]. This persistence could be explained by failures in decontamination procedures [40]; as an example, poultry manure is often kept outside, with or without protection, to be used as fertilizer for nearby market gardening. But these isolates could also be re-introduced into the poultry farm via different routes, such as rodents, or even rainwater; [41] had already demonstrated that Salmonella could be disseminated in the soil as a result of substantial rainfall, frequent in tropical climates such as that of Reunion Island.

The same pulsotypes were found in chickens, poultry houses and the slaughterhouse, confirming that the slaughterhouse had been contaminated by infected chickens $[33,42]$.

The same S. Typhimurium PFGE patterns (B54, B62, B64 and B69) observed for poultry and human isolates underlined a possible contamination of humans by chicken as previously described by Nogrady et al. [43]. The presence of $S$. Typhimurium in broiler chickens is of considerable importance from the standpoint of public health and particularly in Reunion island where it is the most frequent serovar incriminated in food poisoning [44]. Most of these 
Table 3. PFGE and antibiotic susceptibility patterns of Salmonella Typhimurium and Salmonella S.I 4,12:i:- collected from broiler chickens, from farm and abattoir environment, from other animals, and humans (Reunion Island, 2007-2009, 176 isolates).

\begin{tabular}{|c|c|c|c|c|c|c|c|c|c|c|c|c|c|c|}
\hline \multirow{2}{*}{$\begin{array}{l}\text { PFGE } \\
\text { Pattern }\end{array}$} & \multirow{2}{*}{$\begin{array}{c}\text { Number } \\
\text { of } \\
\text { Strains } \\
\text { Associated } \\
(\%)\end{array}$} & \multirow{2}{*}{ R Type } & \multicolumn{12}{|c|}{ Origin } \\
\hline & & & $\begin{array}{c}\text { S 1,4,[5], } \\
12: i:-\end{array}$ & $\begin{array}{l}\text { S. Typhi- } \\
\text { murium }\end{array}$ & $\begin{array}{c}\text { S 1,4,[5], } \\
12: i:-\end{array}$ & $\begin{array}{l}\text { S. Typhi- } \\
\text { murium }\end{array}$ & $\begin{array}{c}\text { S 1,4,[5], } \\
\text { 12:i:- }\end{array}$ & $\begin{array}{l}\text { S. Typhi- } \\
\text { murium }\end{array}$ & $\begin{array}{c}\text { S 1,4,[5],1 } \\
\text { 2:i:- }\end{array}$ & $\begin{array}{l}\text { S. Typhi- } \\
\text { murium }\end{array}$ & $\begin{array}{c}\text { S 1,4,[5], } \\
\text { 12:i:- }\end{array}$ & $\begin{array}{l}\text { S. Typhi- } \\
\text { murium }\end{array}$ & $\begin{array}{c}\text { S 1,4,[5], } \\
\text { 12:i:- }\end{array}$ & $\begin{array}{l}\text { S. Typhi- } \\
\text { murium }\end{array}$ \\
\hline B49 & $2(1.1)$ & & & & & 1 & & & & & & 1 & & \\
\hline B50 & $13(7.4)$ & & & 6 & & 1 & & & & 4 & & & & 2 \\
\hline B51 & $5(2.8)$ & & & & & & & & & & & 5 & & \\
\hline B52 & $5(2.8)$ & & & 4 & & & & & & & & 1 & & \\
\hline B53 & $4(2.3)$ & & & & & 3 & & & & & & 1 & & \\
\hline B54 & $4(2.3)$ & & & & & 1 & & 1 & & 2 & & & & \\
\hline B56 & $1(0.6)$ & & & & & 1 & & & & & & & & \\
\hline B56 & 1(0.6) & $\mathrm{A}, \mathrm{Su}, \mathrm{Sxt}, \mathrm{T}$ & & & & & & & & & & 1 & & \\
\hline B56 & $1(0.6)$ & $\mathrm{Na}, \mathrm{T}$ & & & & & & & & & & 1 & & \\
\hline B57 & $1(0.6)$ & & & & & 1 & & & & & & & & \\
\hline B58 & $1(0.6)$ & $\mathrm{S}, \mathrm{Su}, \mathrm{T}$ & & & & & & 1 & & & & & & \\
\hline B59 & $1(0.6)$ & & & 1 & & & & & & & & & & \\
\hline B60 & $1(0.6)$ & & & & & & & & & 1 & & & & \\
\hline B61 & $1(0.6)$ & & & & & 1 & & & & & & & & \\
\hline B65 & $1(0.6)$ & & & & & 1 & & & & & & & & \\
\hline B66 & $1(0.6)$ & $\mathrm{C}, \mathrm{Su}, \mathrm{Sxt}, \mathrm{T}$ & & & & 1 & & & & & & & & \\
\hline B67 & $1(0.6)$ & & & & & & & 1 & & & & & & \\
\hline B68 & $2(1.1)$ & & & & & 2 & & & & & & & & \\
\hline B69 & $7(4)$ & $\mathrm{A}, \mathrm{S}, \mathrm{Su}, \mathrm{T}$ & 1 & & & 1 & & 1 & 3 & & & 1 & & \\
\hline B70 & $1(0.6)$ & $\mathrm{A}, \mathrm{S}, \mathrm{Su}, \mathrm{T}$ & 1 & & & & & & & & & & & \\
\hline B71 & $3(1.7)$ & $\mathrm{A}, \mathrm{S}, \mathrm{Su}, \mathrm{T}$ & & & 1 & 1 & & & & & & 1 & & \\
\hline B72 & $2(1.1)$ & $\mathrm{S}, \mathrm{Su}, \mathrm{T}$ & & & & & & & & 1 & & 1 & & \\
\hline B72 & $1(0.6)$ & $\mathrm{A}, \mathrm{S}, \mathrm{Su}$ & & & & & & & & 1 & & & & \\
\hline B73 & $18(10.2)$ & $\mathrm{A}, \mathrm{S}, \mathrm{Su}, \mathrm{T}$ & 6 & 1 & & & & & 6 & 4 & & & & 1 \\
\hline B74 & 1(0.6) & $\mathrm{A}, \mathrm{S}, \mathrm{Su}, \mathrm{T}$ & & 1 & & & & & & & & & & \\
\hline B75 & $1(0.6)$ & $\mathrm{A}, \mathrm{S}, \mathrm{Su}, \mathrm{T}$ & & 1 & & & & & & & & & & \\
\hline B76 & $1(0.6)$ & $\mathrm{A}, \mathrm{S}, \mathrm{Su}, \mathrm{T}$ & & & & & & & & & 1 & & & \\
\hline B77 & $11(6.3)$ & $\mathrm{T}$ & & 5 & & & & & & 6 & & & & \\
\hline B78 & $1(0.6)$ & & & & & 1 & & & & & & & & \\
\hline
\end{tabular}


isolates exhibited the same genetic pattern but showed differences in susceptibility to antibiotic drugs. This variability could be explained by genetic changes; mutation or horizontal transfer, linked for example to the selective pressure of drugs at the farm [45].

Multidrug resistance was generally observed in Salmonella Typhimurium [46] but in this study, only three isolates - one from human and two from pigs - exhibited the specific profile ACSSuT. This profile matched the phage type DT104 but it was not the prominent profile in our study. Salmonella Typhimurium DT104 has spread in various countries [47, 48] and it could also be present in Reunion Island. Nevertheless, this resistance profile was not found in chicken isolates; this could be explained by different practices in the poultry and pig industries.

Most Salmonella Typhimurium and Salmonella 1,4,[5],12:i:- isolates were susceptible to all the tested antibiotic drugs in contrast to results observed in mainland France [44]. Most of the isolates from Reunion Island showed resistance to ampicilin, streptomycin, sulfonamides and tetracycline as previously identified [49]. These antibiotic drugs have been the most commonly used antibiotic drugs in animal production in Reunion Island and this explained the frequent occurrence of resistance to these antimicrobial agents $[50,51]$; only one $S$. Typhimurium isolate was resistant to nalidixic acid whereas this resistance has been observed frequently in the USA [52], in Japan [53] and in South-East Asia [54].

Analyses using serotyping and more specifically macrorestriction profiling by PFGE with Xba1 showed that no clonal relationship existed between PFGE and antibiotic resistance profiles. "The antimicrobial resistance characteristics could have been acquired by selective pressure of drugs or by horizontal transfer" [55]. It is therefore necessary to investigate veterinary practices to understand the differences between the pig and poultry industries.

This study strongly indicates a close genetic relationship between S. Typhimurium and $S$. 1,4,[5],12:i:- isolates from humans and broiler chickens. But poultry meat is not the only source of human Salmonella infections however, since the same profiles have been recovered from other animals. And even if the resistance of Salmonella to antibiotic drugs remains low, it also highlights the need for continuous surveillance to monitor antimicrobial resistance in bacteria associated with animals and humans.

\section{CONFLICT OF INTEREST}

The authors confirm that this article content has no conflict of interest.

\section{ACKNOWLEDGEMENTS}

The Authors wish to thank the staff of Avi Pole Reunion for their collaboration in collecting samples from poultry farms: Jef Reichardt, Jacky Berby, Jimmy Hoarau, François Penverne and Yvon Euzen; thanks also to the farmers.

The Authors would also like to thank the staff of the slaughterhouse for their organization of sample collection: Benjamin Boulanger, Eric Pascal and his staff, Stephanie Yeung, Pierre Reype and Guillaume Burel. Thanks to Dr.
Michault, Sandrine Picot (GHSR Reunion) and Dr Rogier for human isolates. The Authors thank all the corresponding laboratories of the French National Reference Centre for Salmonella (FNRC-Salm) network for their collaboration and "The FNRC-Salm is partially funded by the Institut de Veille Sanitaire".

The Authors are grateful to the staff of the AFSSA HQPAP and AFSSA CEB laboratory for their help in molecular analyses.

\section{REFERENCES}

[1] White PL, Baker AR, James WO. Strategies to control Salmonella and Campylobacter in raw poultry products. Revue Scientifique Et Technique (International Office of Epizootics) 1997; 16: 525-41.

[2] Sow AI, Seydi M, Thiaw M, et al. Les salmonelloses au centre hospitalier universitaire de Fann à Dakar : aspects bactériologiques. Médecine et Maladies Infectieuses 2000; 30: 657-60.

[3] Medeiros MI, Neme SN, da Silva P, et al. Etiology of acute diarrhea among children in Ribeiro Preto-SP, Brazil. Revista Do Instituto de Medicina Tropical de Sao Paulo 2001; 43: 21-4.

[4] D'Aoust JY. Salmonella. In: Doyle MP, Eds., Foodborne bacterial pathogens. New York: Marcel Dekker Inc. 1989; pp. 327-446.

[5] Thong KL, Goh YL, Radu S, et al. Genetic diversity of clinical and environmental strains of Salmonella enterica serotype Weltevreden isolated in Malaysia. J Clin Microbiol 2002; 40: 2498-503.

[6] Martinez-Urtaza J, Peiteado J, Lozano-Leon A, Garcia-Martin O. Detection of Salmonella Senftenberg associated with high saline environments in mussel processing facilities. J Food Prot 2004; 67: 25663.

[7] Doran G, Morris D, O'Hare C, et al. Cost-effective application of pulsed-field gel electrophoresis to typing of Salmonella enterica serovar Typhimurium. Appl Environ Microbiol 2005; 71: 8236-40.

[8] Switt AIM, Soyer Y, Warnick LD, Wiedmann M. Emergence, distribution, and molecular and phenotypic characteristics of salmonella enterica serotype 4,5,12:i. Foodborne Pathog Dis 2009; 6: 407-15.

[9] Parry CM. Antimicrobial drug resistance in Salmonella enterica. Curr Opin Infect Dis 2003; 16: 467-72.

[10] Butaye P, Michael GB, Schwarz S, Barrett TJ, Brisabois A, White DG. The clonal spread of multidrug-resistant non-typhi Salmonella serotypes. Microb Infect 2006; 8: 1891-7.

[11] Nakaya H, Yasuhara A, Yoshimura K, et al. Life-threatening infantile diarrhea from fluoroquinolone-resistant Salmonella enterica typhimurium with mutations in both gyrA and parC. Emerg Infect Dis 2003; 9: 255-7.

[12] Cardinale E, Maeder S, Porphyre V, Debin M. Salmonella in fattening pigs in Reunion Island: Herd prevalence and risk factors for infection. Prev Vet Med 2010; 96: 281-5.

[13] Stevens A, Kabore Y, Perrier-Gros-Claude JD, et al. Prevalence and antibiotic-resistance of Salmonella isolated from beef sampled from the slaughterhouse and from retailers in Dakar (Senegal). Int $\mathrm{J}$ Food Microbiol 2006; 110: 178-86.

[14] Popoff MY, Bockemuhl J, Brenner FW, Gheesling LL. Supplement 2000 (no. 44) to the Kauffmann-White scheme. Res Microbiol 2001; 152: $907-9$

[15] Kerouanton A, Marault M, Lailler R, et al. Pulsed-field gel electrophoresis subtyping database for foodborne Salmonella enterica serotype discrimination. Foodborne Pathog Dis 2007; 4: 293-303.

[16] Ribot EM, Fair MA, Gautom R, et al. Standardization of pulsed-field gel electrophoresis protocols for the subtyping of Escherichia coli O157: H7 Salmonella, and Shigella for PulseNet. Foodborne Pathog Dis 2006; 3: 59-67.

[17] Nei M, Li WH. Mathematical-model for studying genetic-variation intyerms of restriction endonucleases. P Natl Acad Sci Usa 1979; 76: 5269-73.

[18] Tenover FC, Arbeit RD, Goering RV, et al. Interpreting chromosomal DNA restriction patterns produced by pulsed-field gel electrophoresis: criteria for bacterial strain typing. J Clin Microbiol 1995; 33: 2233-9.

[19] Hunter PR. Reproducibility and indexes of discriminatory power of microbial typing methods. J Clin Microbiol 1990; 28: 1903-5.

[20] Akoachere J, Tanih NF, Ndip LM, Ndip RN. Phenotypic characterization of salmonella typhimurium isolates from food-animals 
and abattoir drains in Buea, Cameroon. J Health Popul Nutr 2009; 27: 612-8.

[21] van Asselt ED, Thissen J, van der Fels-Klerx HJ. Salmonella serotype distribution in the Dutch broiler supply chain. Poult Sci 2009; 88: 2695701.

[22] Xia SL, Hendriksen RS, Xie ZQ, et al. Molecular characterization and antimicrobial susceptibility of salmonella isolates from infections in humans in henan province. China. J Clini Microbiol 2009; 47: 401-9.

[23] Meerburg J-RW, Wagenaar J, Kijlstra A. Presence of salmonella and campylobacter SPP. in wild small mammals on organic farms. Appl Environ Microbiol 2006; 72: 960-2.

[24] Chadfield M, Skov M, Christensen J, Madsen M, Bisgaard M. An epidemiological study of Salmonella enterica serovar 4, 12:b:- in broiler chickens in Denmark. Vet Microbiol 2001; 82: 233-47.

[25] Burnens AP, Stanley J, Sechter I, Nicolet J. Evolutionary origin of a monophasic Salmonella serovar, 9,12:1,v:-, revealed by IS200 profiles and restriction fragment polymorphisms of the $\mathrm{fljB}$ gene. $\mathrm{J}$ Clin Microbol 1996; 34: 1641-5.

[26] Garaizar J, Porwollik S, Echeita A, et al. DNA microarray-based typing of an atypical monophasic Salmonella enterica serovar. J Clin Microbol 2002; 40: 2074-8

[27] Tsen HY, Lin JS, Hsih HY. Pulsed field gel electrophoresis for animal Salmonella enterica serovar Typhimurium isolates in Taiwan. Vet Microbiol 2002; 87: 73-80.

[28] Rivoal K, Protais J, Queguiner S, et al. Use of pulsed-field gel electrophoresis to characterize the heterogeneity and clonality of Salmonella serotype Enteritidis, Typhimurium and Infantis isolates obtained from whole liquid eggs. Int J Food Microbiol 2009; 129: 1806.

[29] Liebana E, Guns D, Garcia ML, et al. Molecular typing of Salmonella serotypes prevalent in animals in England: assessment of methodology. J Clin Microbol 2001; 39: 3609-16.

[30] Corbett-Feeney G, Riain UN. The use of pulsed-field gel electrophoresis for subdivision of Salmonella typhimurium in an outbreak situation. J Infect 1998; 36: 175-7.

[31] Aarestrup FM. Monitoring of antimicrobial resistance among food animals: principles and limitations. J Vet Med B Infect Dis Vet Public Health 2004; 51: 380-8.

[32] Wong TL, MacDiarmid S, Cook R. Salmonella, Escherichia coli O157:H7 and E. coli biotype 1 in a pilot survey of imported and New Zealand pig meats. Food Microbiol 2009; 26: 177-82.

[33] Rasschaert G, Houf K, Godard C, et al. Contamination of carcasses with Salmonella during poultry slaughter. J Food Prot 2008; 71: 146-52.

[34] Meerburg BG, Kijlstra A. Role of rodents in transmission of Salmonella and Campylobacter. J Sci Food Agr 2007; 87: 2774-81.

[35] Kim A, Lee YJ, Kang MS, Kwag SI, Cho JK. Dissemination and tracking of Salmonella spp. in integrated broiler operation. J Vet Sci 2007; 8: 155-61.

[36] Taylor KD. Rodent problems in tropical agriculture. PANS 1972; 18: 81-8.

[37] Pascal M, Lorvelec O, Borel G, Rosine A. Rodent community structures in agricultural and 'natural' ecosystems of Guadeloupe and Martinique (French West Indies). Revue D Ecologie-La Terre Et La Vie 2004; 59: 283-92.

[38] Refsum T, Heir E, Kapperud G, Vardund T, Holstad G. Molecular epidemiology of Salmonella enterica serovar typhimurium isolates determined by pulsed-field gel electrophoresis: comparison of isolates from avian wildlife, domestic animals, and the environment in Norway. Appl Environ Microbiol 2002; 68: 5600-6.
[39] Marin C, Lainez M. Salmonella detection in feces during broiler rearing and after live transport to the slaughterhouse. Poult Sci 2009; 88: 19992005.

[40] Cardinale E, Tall F, Gueye EF, Cisse M, Salvat G. Risk factors for Salmonella enterica subsp. enterica infection in senegalese broilerchicken flocks. Prev Vet Med 2004; 63(3-4): 151-61.

[41] Chao WL, Ding RJ, Chen RS. Survival of pathogenic bacteria in environmental microcosms. Zhonghua Min Guo Wei Sheng Wu Ji Mian Yi Xue Za Zhi 1987; 20: 339-48.

[42] Cardinale E, Gros-Claude JDP, Rivoal K, et al. Epidemiological analysis of Salmonella enterica ssp enterica serovars Hadar, Brancaster and Enteritidis from humans and broiler chickens in Senegal using pulsed-field gel electrophoresis and antibiotic susceptibility. J Appl Microbiol 2005; 99: 968-77.

[43] Nogrady N, Imre A, Kostyak A, Paszti J, Nagy B. Antibiotic resistance and clonal relationship of Salmonella Infantis strains isolated from broiler chickens and humans in Hungary. Elelmiszervizsgalati Kozlemenyek 2008; 54: 90-100.

[44] D'ortenzio E, Weill F, Ragonneau S, et al. First report of a Salmonella enterica serovar Weltevreden outbreak on Réunion Island, France, August 2007. Eurosurveillance 2008; 13: 393-5.

[45] Usera MA, Aladuena A, Gonzalez R, et al. Antibiotic resistance of Salmonella SPP. from animal sources in Spain in 1996 and 2000. J Food Protect 2002; 65:768-73.

[46] Bertrand S, Weill FX, Cloeckaert A, et al. Clonal emergence of extended-spectrum beta-lactamase (CTX-M-2)-producing Salmonella enterica serovar Virchow isolates with reduced susceptibilities to ciprofloxacin among poultry and humans in Belgium and France (2000 to 2003). J Clin Microbol 2006; 44: 2897-903.

[47] Olsen JE, Skov MN, Threlfall EJ, Brown DJ. Clonal lines of Salmonella enterica serotype Enteritidis documented by IS200-, ribo-, pulsed-field gel electrophoresis and RFLP typing. J Med Microbiol 1994; 40: 15-22.

[48] Glynn MK, Bopp C, Dewitt W, et al. Emergence of multidrug-resistant Salmonella enterica serotype typhimurium DT104 infections in the United States. N Engl J Med 1998; 338: 1333-8.

[49] White DG, Zhao S, Simjee S, Wagner DD, McDermott PF Antimicrobial resistance of foodborne pathogens. Microbes and Infection / Institut Pasteur 2002; 4(4): 405-12.

[50] Threlfall EJ, Teale CJ, Davies RH, et al. A comparison of antimicrobial susceptibilities in nontyphoidal salmonellas from humans and food animals in England and Wales in 2000. Microb Drug Resist 2003; 9 ; 183-9.

[51] Chuanchuen R, Pathanasophon P, Khemtong S, Wannaprasat W, Padungtod P. Susceptibilities to antimicrobials and disinfectants in Salmonella isolates obtained from poultry and swine in Thailand. J Vet Med Sci 70: 2008; 595-601.

[52] Sjolund-Karlsson M, Folster JP, Pecic G, et al. Emergence of plasmidmediated quinolone resistance among non-typhi salmonella enterica isolates from humans in the United States. Antimicrob Agents Chemother 2009; 53: 2142-4.

[53] Izumiya H, Mori K, Kurazono T, et al. Characterization of isolates of Salmonella enterica serovar typhimurium displaying high-level fluoroquinolone resistance in Japan. J Clin Microbol 2005; 43: 5074-9.

[54] Hakanen AJ, Lindgren M, Huovinen P, et al. New quinolone resistance phenomenon in Salmonella enterica: nalidixic acid-susceptible isolates with reduced fluoroquinolone susceptibility. J Clin Microbol 2005; 43: 5775-8.

[55] LeClerc JE, Li B, Payne WL, Cebula TA. High mutation frequencies among Escherichia coli and Salmonella pathogens. Science 1996; 274 : 1208-11.

This is an open access article licensed under the terms of the Creative Commons Attribution Non-Commercial License (http://creativecommons.org/licenses/by-nc/3.0/) which permits unrestricted, non-commercial use, distribution and reproduction in any medium, provided the work is properly cited. 